\title{
PROCESSODEIMPLEMENTAÇÃODEAMBIENTESINFORMATIZADOSEA PRÁTICADOCENTE
}

\author{
Deise Juliana Francisco \\ Mabel Cristina Dal Toé2 \\ Taís Fim Alberti ${ }^{3}$
}

\section{Resumo}

Este trabalho discute o processo de implementação de laboratório de informática educativa em escola estadual da região missioneira do Estado do Rio Grande do Sul. Constitui-se em estudo de caso que utiliza metodologia qualitativa na coleta e leitura de dados. Foram realizadas entrevistas semi-estruturadas com 27 docentes do Ensino Fundamental atuantes em três turnos e três coordenadores do ambiente informatizado da escola. A escolha dos sujeitos foi aleatória. Como resultado aponta-se o processo de implementação desvinculado da proposta da escola, constituído de forma não-participativa, direcionado para os alunos. Elencam-se atravessamentos ocorridos nesse processo, tais como a forma como se deu o processo de implementação, entendimento dos docentes sobre informática na educação, conhecimento dessa área. Citam-se as dificuldades e os modos de implementação do ambiente informatizado. Na discussão, são analisados os resultados na perspectiva das tecnologias da comunicação e informação e a dificuldade de mudança em estabelecimentos que atuam no processo de ensino-aprendizagem.

Palavras-Chave: informática educativa; ambientes informatizados; escola e tecnologia.

\section{THE PROCESS OF COMPUTER IMPLEMENTATION AND THE TEACHER'S WORK}

\begin{abstract}
The present report analyses the implementation of an educational computerised laboratory process in public schools in the Southwest region of Rio Grande do Sul State. This project consists of a study case that uses qualitative methodology based on data collecting and reading. Semi-structured interviews have been done with 27 teachers from board of elementary education who work in the three different daily shifts as well as with three coordinators of the school computerised environment. The selection of candidates has been made at random. As a result we have a non-participate implementation process not connected to the school offer, directed to the pupils. Categorising the mishaps that have occurred during the corresponding process: the way the implementation process was carried out, the people understanding on the computerised educational process and the respective area of knowledge. The difficulties of the implementation process of the computerised system environment are also mentioned. In this discussion, the results of the communication and information technologies are properly analyzed as they affect the teaching and learning process.
\end{abstract}

Key words: computer implementation; teacher's work; computers and school.

\section{INTRODUÇÃo}

\section{Escola e professoralidade}

A escola básica é uma instituição historicamente construída, recente, sendo uma das responsáveis pela socialização e passagem obrigatória para as crianças. A escola pública, obrigatória e gratuita foi instituída no início do século XX, na Europa. Os professores passaram a ser funcionários públicos do Estado, e foram adotadas medidas para proibir o trabalho infantil. $\mathrm{Na}$ verdade, de acordo com Varela (citado por Eizirik \& Comerlato, 1995) desde o século XVI existia uma série de dispositivos que instrumentalizam sua constituição, surgindo, então, um espaço fechado, específico, destinado à educação das crianças.

Conforme Varela (1994) salienta, no fim do século XVIII, em conexão com o processo de pedagogização do conhecimento, produziu-se outra transformação, a do disciplinamento interno dos saberes. O estado por de agentes legitimados pôs em ação uma série de dispositivos com a finalidade de se apropriar dos saberes, de discipliná-los e de pô-los a seu serviço. Em relação a

\footnotetext{
${ }^{1}$ Professora de Psicologia da Universidade Regional Integrada do Alto Uruguai e das Missões - URI - Campus Santo Angelo

${ }^{2}$ Psicóloga Escolar.

${ }^{3}$ Graduanda em Psicologia pela Universidade Regional Integrada do Alto Uruguai e das Missões - URI - Campus Santo Ângelo - bolsista PIIC/URI
} 
esse movimento de reestruturação do campo do saber, estabeleceram-se novas relações entre saberes e poderes. Cada saber devia se constituir em forma de disciplina, dentro de um campo global, a ciência, um campo que enfrentava a divisão dos saberes, sua classificação e hierarquização.

No ambiente escolar, vários dispositivos foram criados, um deles é o currículo. Como afirma Silva (1995), o currículo não é um meio neutro de transmissão do conhecimento, pois, ao determinar quem está autorizado a falar, quando, sobre o quê, quais conhecimentos são autorizados, legítimos, o currículo controla, regula e governa. Historicamente, a escola é um dispositivo de governo e regulação moral dos indivíduos e, no centro desse processo, está o currículo, formando a ligação entre o conhecimento e as regras que determinam sua transmissão. Identificar e questionar os atuais regimes de regulação inscritos no currículo significa abrir a possibilidade de contestar e modificar aquelas relações de poder que tendem a excluir certos saberes e grupos sociais, o que tende a estigmatizá-los e a inferiorizá-los.

No momento em que já avançamos em direção a sociedades pós-disciplinares, essa disciplinarização continua ainda vigente no que se refere aos saberes, por do currículo escolar, dos programas fechados e dos saberes organizados por matérias, e essas ainda são subdivididas por unidades temáticas, sendo interessante romper o círculo vicioso criado pela disciplinarização dos saberes e dos sujeitos. A escola não é somente um lugar de socialização onde se vai experimentar métodos e técnicas, avalizados pelo professor, mas também uma instância de subjetivação, pois é uma instituição social que emerge enfrentando outras formas de socialização e de transmissão de saberes. Nesse sentido, o sujeito está imerso em complexas relações de poder, além de relações de produção e de significação.

É uma instância materializada tanto no espaço quanto na apropriação do tempo. Esses elementos são entendidos por Certeau (1994) e Escolano (1994) na constituição escolar. A escola constitui-se em espaço privilegiado na produção do sujeito moderno, tornandose o lugar onde se ensina uma nova noção de tempo e de espaço, e a internalização de tais noções é para a construção dos sujeitos sociais, ela se faz por meio das mentes e dos corpos em pluralidade e diversidade. Dessa forma, o espaço é constituidor de sujeito com proibições, sanções e permissões o que implica relação de poder. Tal funcionamento é baseado em divisões de clas- se, gênero, idade que determinam as formas com que os sujeitos vivem e percebem o tempo e o espaço no seu dia-a-dia, e na vida pessoal e da comunidade.

Lugar e espaço são conceitos que permitem operacionalizar o que acontece entre os muros escolares. Certeau (1994) diz que um lugar é a ordem, seja qual for, segundo o qual se distribui elementos nas relações de coexistência. Tal lugar que pode ser conhecido ou desconhecido por alunos, docentes e transeuntes é cotidianamente habitado, caminhado, visto, sentido, paredes tocadas, texturadas e sentidas. Francisco (1997) observa que as relações são construídas no deslocamento, no habitar, nos locais onde se pode andar e onde não se pode, quais as regras que permitem, ou não, que determinados agentes transitem na hora do recreio, na sala de docentes, por exemplo. Assim, pode-se observar que o espaço escolar também fala aos sujeitos. Escolano (1994) afirma que "arquitetura escolar é também por si mesma um programa, uma espécie de discurso que institui, em sua materialidade, um sistema de valores como ordem, disciplina e vigilância” (p. 100). Um dos agentes privilegiados que participa do cotidiano escolar é o professor. Isso nos remete a pensar que ser docente implica estar em um constante devir, se construído a cada dia com o coletivo onde está inserido.

Costa (1995) aponta que as categorias "professor" e "escola" foram construídos historicamente e inter-relacionadas, vinculadas aos processos e práticas sociais que produzem os sujeitos sociais. Os estabelecimentos escolares tiveram, pois, um grupo ocupacional (professores) com funções de controlar e com autoridade no cotidiano escolar. O professor também constitui-se em sujeito escolar. Pereira (2000) conceitua a 'professoralidade' como uma marca produzida, uma constituição de saberes e práticas. Não é uma identidade, pois esta seria uma formação existencial já modelada, pronta seguindo um caminho determinado, condicionadamente. Seria construir-se como sujeito seguindo sempre o mesmo modelo institucional ou cultural determinado, algo natural.

Vir a ser professor é vir a ser algo que não se vinha sendo, é diferir de si mesmo e por ser uma diferença, não poderá ser a recorrência a um mesmo padrão ou modelo, ele não pode ser um estado estável do sujeito, pois a 'professoralidade' é um estado em risco de desequilíbrio permanente. Justamente como foi citado, ser professor é um constante vir a ser e, portanto, ter vindo a ser professor, estar sendo professor é a atuali- 
zação de uma dentre inúmeras potencialidades que perfazem o campo da subjetividade.

\section{Escola e tecnologias da comunicação e informação}

As transformações que hoje acontecem no mundo todo vão muito além de uma simples mudança de tecnologia de comunicação e informação. Elas desempenham um papel central, principalmente na Educação, que vem se debatendo e questionando muito esse assunto, já que a escola constitui um processo permanente de construção de pontes entre o mundo da escola e o universo que nos cerca. $\mathrm{O}$ educador será o mediador desse processo, mas, para isso, não basta implementar ambiente informatizado, inserir computadores em uma escola, mas, sim, deve-se trabalhar de uma forma a promover uma mudança cultural, visão produtiva desse conjunto de instrumentos. Nesse sentido, a Educação deve enfocar novas competências: mudanças desta magnitude requerem um completo repensar da Educação, tanto em termos de currículo como no desenvolvimento de novas pedagogias que possam assegurar que cada aluno alcance o nível elevado de habilidades necessárias para lidar com um mundo dinâmico no século XXI (Thornburg, 1997).

Como observa Lévy (1993), os modos de aprender e de ser estão intrinsecamente conectados. Os modos de conhecer que estão imbricados com o desenvolvimento de diferentes tecnologias ao longo da história, desde as tecnologias orais, da escrita e da informática. Maraschin (2000) considera que a definição da ecologia cognitiva se dá pelas vias informacionais privilegiadas: "vias que não somente suportam, possibilitam, mas que também constituem, constróem as trocas informacionais, configurando redes iterativas que definem as lógicas e as práticas do conhecer" (p. 56).

A sociedade digital tem uma grande ampliação de possibilidades e envolvimento, não existe um ponto fixo ou posições definidas, mas, sim, linhas interconectadas que se inter-relacionam. Ela não se caracteriza pela exclusão ou oposição aos modelos anteriores de aquisição e utilização dos conhecimentos armazenados na memória humana ou cibernética. Kenski (1998) aponta que "a velocidade das alterações na esfera de produção de conhecimentos e informações ocasiona a duração efêmera das múltiplas mensagens e desobriga os sujeitos do exercício de retê-las, como verdade" (p. 67).

Para tanto, cabe ressaltar a observação de Lévy (1993) "as mudanças das ecologias cognitivas devidas, entre outros, à aparição de novas tecnologias intelectuais ativam a expansão de formas de conhecimentos que durante muito tempo estiveram relegadas a certos domínios, tem como enfraquecimento de certo estilo de saber, mudanças de equilíbrio, deslocamentos de centro de gravidade" (p. 29). As tecnologias estão presentes em todos os lugares, as pessoas estão cercadas de tecnologias que tornam a vida mais fácil. Transformam o tempo e redimensionam muitas concepções da atualidade, o que implica uma série de mudanças, novas aprendizagens, adaptações que precisam ser inseridas no nosso dia-a-dia; assim, não se pode ignorar a presença da tecnologia, tão pouco sua importância.

Da mesma forma, é preciso que o professor se posicione não como um detentor de conhecimento, mas como um parceiro, que encaminha e orienta o aluno diante das diversas possibilidades e formas de alcançar o conhecimento e de se relacionar com ele. Isso não significa uma adesão incondicional, muito menos uma oposição radical, mas significa criticamente conhecê-los para saber quais são suas vantagens e desvantagens, seus riscos e possibilidades, para transformá-los realmente em ferramentas, as quais pode dispensar em certos momentos e torná-la parceira em outros, conforme afirma Kenski (1998).

Segundo a mesma autora, as velozes transformações tecnológicas da atualidade impõem novos ritmos e dimensões á tarefa de ensinar e aprender. É preciso que se esteja em permanente estágio de aprendizagem e de adaptação ao novo. Na profissão docente, com a nova discursividade que surge consoante às novas tecnologias, a questão da autoridade é colocada em xeque. Esse fato é percebido em muitas escolas quando da inserção dos computadores, o professor acaba se desconstruindo de uma forma, muitas vezes, negativa porque acredita que, com a inserção das novas tecnologias, o seu papel fica meio descaracterizado. Toda a discussão sobre as novas tecnologias, na verdade, pretendem recolocar esse lugar de conhecimento e recolocar a escola. Nesse sentido, há a necessidade de recolocar fundamentalmente a profissão docente.

Esta pesquisa insere-se no momento político-educacional brasileiro do incentivo ao uso de tecnologias informáticas em escolas pelo governo federal, na discussão sobre o ensino na contemporaneidade e os vários modos de ensinar. Visa contribuir na busca de caminhos para a qualificação do processo de ensino-aprendizagem no uso de tecnologias da comunicação e informação. Optou-se por fazer um recorte de pesquisa que 
acompanhou o cotidiano de uma escola, mapeando as relações que se desenvolviam entre as diversas agências implementadoras das tecnologias da comunicação e informação e o uso da tecnologia. Foram considerados para este estudo elementos sobre a implementação do ambiente informatizado e sobre sua possível consolidação em escolas.

A orientadora e as bolsistas acompanharam a implementação do projeto proposto pela escola ao Ministério da Educação e Cultura (MEC), realizaram observações de professores e alunos no momento da aula de informática. Com isso, pretendeu-se mapear as possíveis modificações na prática docente quanto ao uso de tecnologias informáticas. Além disso, objetivou-se reconhecer alguns discursos sobre a informática educativa, com base em uma perspectiva de discurso não apenas como enunciação de falas, mas também como articuladores de práticas socioeducativas e de modos de subjetivação.

\section{MÉTODO}

\section{Situação}

A abordagem metodológica utilizada na pesquisa é de cunho qualitativo. Constitui-se de estudo de caso de uma escola pública estadual, localizada na zona urbana (centro) no noroeste do eEstado do Rio Grande do Sul, que foi selecionada por estar iniciando o processo de implementação de um ambiente informatizado.

A escola foi fundada em 1924, oferece atualmente Educação Infantil, Ensino Fundamental e Ensino Médio distribuídos em três turnos de funcionamento. Em 2000, a escola contou com um quadro de recursos humanos constituídos por 73 professoras, 14 professores, 14 funcionários e uma odontóloga. O corpo discente é formado por cerca de 1.500 alunos.

\section{Sujeitos}

Foram entrevistados 27 professoras e uma professor do Ensino Fundamental, atuantes nos três turnos de funcionamento escolar (manhã, tarde e noite).

\section{Procedimento}

A coleta de dados foi realizada por fontes orais, documentais (regimento escolar e projeto de informática educativa) e de observações. A busca de dados foi centrada em observações do cotidiano escolar, coleta de depoimentos, sendo realizadas entrevistas semi-estruturadas. Tais observações constituíram um diário de campo, composto por registros do ambiente de trabalho por meio de anotações, bem como de apontamentos sobre fatos significativos, percepções, entre outros, os quais serviram como subsídios para as análises das táticas e práticas.

As entrevistas foram gravadas com devida permissão, e depois transcritas. A entrevista semi-estruturada contou com questões abertas que possibilitavam ao entrevistado discorrer sobre seu envolvimento com as atividades desenvolvidas no laboratório de informática da escola, sobre seu entendimento sobre informática educativa, além dos dados de identificação (idade, sexo, área de formação, tempo de formação, disciplina que leciona na escola, tempo de trabalho na escola). O roteiro da entrevista foi composto das seguintes perguntas: Qual é a sua opinião sobre o uso da tecnologia na educação? Em geral e dos computadores? O que pensa da proposta de aula por projetos? Teve algum envolvimento no desenvolvimento do projeto na escola, o projeto no qual ganharam o Laboratório? Qual é a sua participação nos projetos dos alunos, no que se refere à sua disciplina? Fez curso no NTE, ou outro na área de informática? Tem conhecimento na área? Tem interesse em fazer algum curso? (Por que não fez ainda?) Como avalia a utilização da informática para os alunos? Ela desenvolve alguma coisa (habilidade, capacidade...)? Qual a sua opinião sobre a forma como está se dando a implementação do ambiente informatizado aqui na escola? Leva em conta na hora de preparar a aula, os recursos disponíveis no laboratório de informática da escola?

\section{ANÁLISE DE DADOS}

Procedeu-se a utilização de análise de conteúdo das entrevistas, sendo os dados interpretados à luz do referencial teórico proposto. Práticas e falas sobre informática educativa foram descritas, seguindo-se uma revisão de literatura no tocante ao assunto.

A partir das entrevistas dos docentes, foram eleitas categorias a partir do agrupamento das falas segundo os núcleos de sentido ao qual se referiam. O mesmo procedimento foi realizado com as coordenadoras do ambiente informatizado. Os dados foram organizados em categorias tais como: Implementação do projeto essa categoria refere-se a dados pertinentes (falas e observações) ao processo de implementação da informática educativa na escola, desde sua preparação até a forma efetiva de vinculação no cotidiano escolar; 
Concepções sobre informática educativa - essa categoria diz respeito às informações que os professores tinham a sobre o uso da informática na educação e quais suas concepções sobre ela; Reações dos professores frente ao uso das novas tecnologias de comunicação nessa categoria foram consideradas as falas dos professores em relação às fantasias que surgiram, o medo que sentem de serem substituídos pela máquina e suas concepções sobre o uso das novas tecnologias pela escola em questão.

\section{RESULTADOS E DISCUSSÃ0}

Dos entrevistados, $82 \%$ possui graduação e é formado a no mínimo 7 anos e no máximo 28 anos. Suas idades variam entre 29 e 50 anos. Entre os sujeitos estavam representantes de todas as áreas de ensino e que lecionavam na escola nos três turnos de funcionamento escolar.

Quanto à implantação, o projeto foi pensado em cinco dias por duas orientadoras da escola, sendo construído sem a participação do coletivo escolar. Atualmente uma delas é a coordenadora - geral do laboratório e coordena o turno da manhã, e é também a vice-diretora do Ensino Médio, a outra é a atual diretora da escola. A escola possui três coordenadoras, uma responsável por cada turno, duas delas foram contratadas somente para realizar essa função. Não possuem nenhuma experiência com Educação, e passaram por uma triagem feita pela delegacia de ensino.

O laboratório possui onze computadores ligados em rede sendo um deles o servidor, duas impressoras e um scanner. Como as turmas possuem em torno de 30 alunos cada é necessário que os projetos sejam realizados em grupo, cada grupo escolhe a temática que desejar. Não há internet, pois a escola não possui recursos financeiros para sustentar os custos de tal investimento. Houve demora na chegada dos recursos computacionais na escola. Em virtude da burocracia estatal, o laboratório levou cerca de dois anos para ser implementado. A sala do laboratório ficou pronta e sem poder ser ocupada por todo esse tempo.

A escola não foi envolvida em discussões preliminares sobre informática educativa e os docentes não foram estimulados a construir conjuntamente uma forma de utilização, o que se confirma em algumas falas: "Foi uma coisa desenvolvida, determinada pelo pessoal que coordena o laboratório. A gente conhecia a idéia, mas..." ".Disseram-nos como seriam as aulas, mas não me lembro se fomos consultadas para dar contribuição ou sugestões para a estrutura das aulas, a princípio não, a não ser que ela (coordenadora) tenha feito isso num dia que eu não vim".

A organização do ambiente informatizado na escola se dá pelo horário chamado horário flutuante, que foi elaborado pela coordenadora - chefe, de maneira que todas as turmas passassem pelo laboratório em seu próprio turno de aula e de forma que, gradativamente, utilizassem todos os horários e todas as disciplinas. Sendo assim, todos os professores teriam acesso a todos os trabalhos de todos os seus alunos. Mas, pelo contrário, tal horário dificultou o acesso dos professores ao laboratório, por não ser um horário pré-fixado, e também por não possibilitar que os professores utilizassem a sala do laboratório em momentos que desejassem, para realizarem alguma tarefa com seus alunos na sua disciplina. Conforme suas falas: "Esse horário não dá liberdade para fazer o trabalho fora de hora. Eu achava que isso aí seria um grande negócio ia produzir muito mais". "Eu acho que a gente acha que poderia ser mais, né? Os alunos têm um horário assim, um pouco restrito, poderiam ser proporcionados mais aulas".

Na perspectiva dos professores, a implementação do projeto deveria oferecer mais horários aos seus alunos. Com relação às atividades desenvolvidas no ambiente informatizado essas eram na sua maioria de utilização pontual, sem perspectiva de desenvolvimento de projetos por parte dos professores, pois o planejamento das atividades desenvolvidas no laboratório foi feito, ou sugerido pela coordenadora, sem ser planejado com os professores.

Os contatos com os professores e com a coordenadora com o intuito de discutir aspectos sobre o ambiente informatizado aconteceram apenas em espaços oficiais de reunião para tratar de questões organizativas e propostas de uso determinadas pela própria coordenadora, até mesmo o horário de funcionamento do laboratório. Em relação ao engajamento na utilização dos recursos informáticos por parte dos professores em sua prática pedagógica, esses delegavam a responsabilidade da atividade desenvolvida à coordenadora do ambiente informatizado.

Quanto às concepções sobre informática educativa, quando foi perguntado sobre sua concepção sobre informática educativa, os professores avaliavam que "é ótimo, que as crianças precisam aprender com as 
tecnologias da comunicação e informação", "acho bom, desenvolve a motricidade", "acho que desenvolve muita coisa, raciocínio, agilidade, tudo, desenvolve tudo". Poucos docentes deram respostas em que listavam mudanças qualitativas nos alunos com o uso do ambiente informatizado na educação. Porém, não se responsabilizam por esse processo, acabam por não perceber que são ferramentas fundamentais para que haja uma utilização correta desse instrumento colocado dentro da escola e que ele realmente ajude no processo de construção de uma nova escola.

Grande parte dos professores fez a capacitação no NTE, mas poucos deles têm noção do que seja informática educativa, até sabem sobre a proposta do ensino dos projetos, e gostam dela, mas não sabem o porquê dela, qual sua finalidade, continuam alheios ao que realmente deveria ser trabalhado no laboratório: "O que eu vou te dizer. Eu não conheço outras formas, só se pode opinar quando tem um envolvimento, conhecimento. Não sei se é a melhor, não conheço outras formas de trabalhar". "Eu acho que de repente seria melhor em turno inverso". "Eu não tenho, assim, outras experiências, não conheço outros lugares, só aqui na escola".

No que tange às reações dos professores frente ao uso das novas tecnologias de comunicação, constatou-se que o computador não aparece enquanto instrumento que os docentes podem utilizar em sua prática diária, 94\% desses docentes não levam em conta na hora de preparar suas aulas os recursos do laboratório de informática e $57 \%$ declaram não ter contribuído para a participação no projeto de seus alunos, no que se refere à sua disciplina.

Quando questionou-se sobre a participação em atividades desenvolvidas no laboratório de informática, os professores apontam várias justificativas: "Eu ia com eles, ficava lá, mas eu não sei quase nada de computação, e também fui poucas vezes, são turmas grandes e era difícil só para a professora que cuidava lá". "Eu participava no sentido que eu vinha, os professores tinham que estar junto aqui na aula de informática com os alunos, estar acompanhando, daí eu dei algumas orientações quanto à ortografia, concordância". "Esse ano eu fiquei bem fora. Participei muito pouco com eles, até quando eles iam para sala de informática eu quase nem ia junto".

Conforme as observações e entrevistas, alguns professores se negaram a deixar suas turmas irem até o laboratório durante os períodos sob sua regência, alegando que o conteúdo estava atrasado e, mesmo quan- do iam com os alunos até o laboratório, não os auxiliavam significativamente, em virtude, segundo eles, do fato de os projetos desenvolvidos não estarem relacionados a suas disciplinas específicas.

Surgiram apenas algumas formas isoladas de participação e contribuição no trabalho dos alunos, conforme a fala de uma professora: "Eu ia com meus alunos, e ajudava no que era necessário, mas não tinha a ver com minha disciplina, especificamente. Fiz um curso a distância com a turma 73 e daí a gente ia trabalhando. Eu dava umas atividades disparadoras, que daí surgissem conteúdos que eles quisessem estudar, trabalhar. Aí eu trabalhei nas aulas de Português, incentivei e ajudei a partir das dúvidas e certezas deles no projeto que estavam fazendo no laboratório. Fizeram história em quadrinhos, esse trabalho a gente lançou na Internet e foi feito em parceria com o NTE. A professora de Inglês também trabalhou com eles, então caminhamos um pouquinho para a interdisciplinariedade. Já houve uma união, e o que ajuda são os temas que eles escolhem que são super fáceis. A $7^{a}$ série gosta de saber sobre sexualidade, então, fecha com Biologia, Religião, e outras disciplinas".

Observou-se que a coordenação do laboratório dáse de forma centralizadora com relação à jornada de decisões que tenham alguma relação com o laboratório. Tudo em relação ao ambiente informatizado e todas as decisões são tomadas pela coordenadora responsável pelo laboratório, desde o horário de funcionamento, a organização das aulas, até definições como, por exemplo, decidir se e por que uma determinada turma não pode mais ter aula no ambiente.

Uma das dificuldades encontradas no processo de implementação do projeto na escola deve-se a essa estrutura. Apesar das propostas inovadoras no ensino e da construção de projetos integrados, ao chegar no cotidiano escolar tais projetos esbarram na organização da escola por turnos, disciplinas, e pela distribuição docente em campos do saber ainda fragmentados. Como, numa estrutura dessas, implementar projetos coletivos? Então, uma das questões levantadas para a escola refere-se a esse aspecto.

Nesse sentido, tira-se a responsabilidade única do processo de implementação da figura do professor e observa-se a estrutura escolar/curricular. Para, além disso, apontou-se a dificuldade em mudar práticas tradicionais que já estão enraizadas e do processo que ocorre na passagem desses momentos. Alguns professores têm a seguinte percepção: "Sem o professor na, disciplina a tecnologia não adianta em nada. Ela é um auxílio". 
A organização da escola por currículo, a idéia dos professores de que a aula de informática deva ser incluída nele, confirmam o total desconhecimento do que seja informática educativa e de sua proposta. Confirma, também, a não - participação e falta de discussão, pelo desejo de toda escola, da implementação de computadores em seu cotidiano, evidenciando-se, mais uma vez, que só pode haver sucesso nessa implementação se todos os professores se derem conta do papel que precisam exercer enquanto tal, para que seus alunos realmente aprendam para que seja instigado neles o desejo por aprender, que sejam capazes por eles mesmos de tirarem suas dúvidas e incertezas.

$\mathrm{Na}$ escola pesquisada, foram registradas marcas de desassossego. Nesse momento materializadas em resistência no uso do ambiente sem planejamento e em avaliações fantasiosas e a resposta aos conflitos alocadas no futuro, como se o passar do tempo pudesse resolver os conflitos entre implementação centralizada e utilização coletiva dos recursos disponíveis na escola.

A escola garantiu o laboratório. Então, alguns professores deram início à capacitação no NTE, mas esses não se apropriaram do espaço do ambiente informatizado, acabaram por não discutir a relação dessa instalação na escola com a proposta pedagógica e com as mudanças no saber contemporâneo. E, por não se apropriarem desse assunto, digeri-lo, assimilá-lo, não se apropriaram do ambiente, já que na verdade não sabem o que deve ser feito e, qual a importância do ambiente informatizado para a Educação.

Um dos objetivos do projeto da escola pesquisada era a interdisciplinaridade. O horário flutuante foi pensado a fim de possibilitar a passagem por todas disciplinas e professores, mas, o que tem acontecido é a escassa presença de professores e o encaminhamento das atividades efetuadas pela coordenadora. As dúvidas e os questionamentos deveriam partir do aprendente e não do docente como elemento organizador da aprendizagem. Percebe-se uma filosofia de ensinoaprendizagem nessa proposta que tenta se articular com o estabelecidona escola (horários, divisão por disciplinas, docentes com pouco horário). Assim, o uso do horário flutuante é a materialização de algumas dificuldades que propostas diferenciadas das que utilizam o pedagogia tradicional encontram. Não há como dar ênfase ao desejo de conhecer individual em um sistema de ensino centralizado e hierarquizado.

Destacando a importância do professor, Collis (1996) observa que o docente é a variável crítica no uso dos computadores na escola quanto à avaliação dos projetos governamentais de informática, pois é sobre eles que as considerações recaem (grau de entendimento, utiliza- ção, intenções, proposta pedagógica, articulação com o currículo escolar, etc). Aponta níveis de problemas no uso de computadores na Educação. O primeiro nível de problemas refere-se às dificuldades no uso de computadores por parte da comunidade escolar e envolve: brigas com as máquinas e grande dispêndio de tempo; falhas no funcionamento de computadores e de softwares; número escasso de computadores; falta de acesso aos computadores; inadequação das máquinas (computadores antigos, lentos, com memória limitada); falta de tempo para aprendizagem dos professores, entre outros. O segundo nível de problemas diz respeito à dificuldade de integração do computador ao ensino, o software é tido, enquanto não eficiente ou apropriado para os objetivos do ensino. Posteriormente, alguns resultados positivos são descritos, porém são limitados a lições (tarefas educativas) individuais, bem como a professores e/ou estudantes. Assim, acaba havendo uma relação entre bons professores e o uso de computadores, tornandose uma experiência isolada da escola como um todo e imputada a características pessoais, sem ampliação e disseminação para outros docentes.

O processo, pelo qual a escola missioneira do presente estudo passa, encontra-se no primeiro nível, o do encontro com a tecnologia. Isso pode ser explicado pelo pouco tempo de uso de tais aparatos na escola, mas principalmente pelo modo de implementação executado. Essa forma de apropriação encontra-se vinculada ao modo de implementação centralizado e da falta de discussão pedagógica sobre a introdução de elementos novos no cotidiano escolar, no caso, o ambiente informatizado.

A principal dificuldade encontrada em articular o projeto com o restante da escola foi determinada pela forma pouco participativa de todo o corpo docente na inserção desta tecnologia na escola, desde a construção do projeto enviado ao MEC para obtenção do laboratório. Retomando os trabalhos de Oliveira (1997) em escolas da rede estadual de Pernambuco quando afirma que "como o restante da escola não foi envolvido nas discussões preliminares, os próprios professores ligados aos projetos não foram estimulados em seus momentos de capacitação a discutir esta problemática" (p.162). O que se confirma na escola com essas falas "Na verdade ninguém consultou a gente, imagino que isso venha de cima", "foi uma coisa desenvolvida, determinada pelo pessoal que coordena o laboratório. A gente conhecia a idéia, mas ..." 


\section{Conclusões}

O presente trabalho foi iniciado com muitas questões a responder, mas até agora conseguimos responder apenas algumas. Mas este estudo permitiu-nos levantar alguns pontos conclusivos sobre o processo de implementação do ambiente informatizado na escola.

Em relação à organização do ambiente informatizado e à forma como essas tecnologias da comunicação e informação entram na escola, pode-se dizer que mesmo a escola tendo uma pedagogia por projetos que embasava toda a prática realizada nesse ambiente, não foi possível desconstruir a aula tradicional, pois os professores não se apropriaram dessa nova ferramenta colocada para dentro dos muros escolares. Não houve uma preparação do estabelecimento escolar para a inserção dos computadores no cotidiano escolar nem a opção prévia do uso de tal ferramenta no ensino. As velozes transformações tecnológicas impõem novos ritmos e dimensões à tarefa de ensinar e aprender, é preciso estar em permanente estado de aprendizagem e de adaptação ao novo. A questão atual é: como utilizar a informática de forma mais proveitosa e educativa possível?

\section{REFERÊNCIAS}

Certeau, M. (1994). A invenção do cotidiano: artes de fazer. Petrópolis, RJ: Vozes.

Costa, M. R. V. (1995). Trabalho docente e profissionalismo. Porto Alegre: Sulina.

Collis, B. (1996). The internet as an educational innovatio: lessons from experience with computer implementation. Educational Technology, 36, (6), 21-30.

Eizirik, M. F., \& Comerlato, D. (1995). A escola (in)visível: jogos de poder/saber/verdade. Porto Alegre: Ed. Universidade UFRGS.

Escolano, A. (1994). La arquitetura como programa. EspacioEscuela y curriculum. História de la Educación. Revista Inmteruniversitaria, (12-13).

Francisco, D. J. (1997). Hibridizações no cotidiano escolar: escola e "novas" tecnologias da comunicação e informação. Dissertação de Mestrado, Universidade Federal do Rio Grande do Sul, Porto Alegre-RS.

Kenski, V. M. (1998). Novas tecnologias: o redimensionamento do espaço e do tempo e os impactos no trabalho docente. Revista Brasileira de Educação - São Paulo, 8.

Lévy. P. (1993). As tecnologias da inteligência: o futuro do pensamento na era da informática. Rio de Janeiro: Ed. 34.

Maraschin, C. (2000). Redes socioculturais e as novas
Nesse âmbito de disputa (formação docente e naturalização das tecnologias) é que a escola em questão encontra-se. Desejo de utilizar, processo centralizado. Um aspecto inicial da inserção de computadores na escola é o processo de aceitação/rejeição das máquinas no cotidiano escolar. Nesse sentido, vários aspectos entram em jogo: quem introduziu os computadores? Qual a relação dessa pessoa/grupo/instituição com a escola? Que aspectos estão presentes implicitamente na presença e no uso de computadores, ou seja, questões base que podem boicotar ou não a utilização pedagógica das máquinas? Outro aspecto é referente ao uso que a instituição fará desse novo elemento. Será apenas um elemento a ser "tragado" pela ordem institucional? Ou poderá trazer novas formas de relacionamento? Nesse sentido, os atores institucionais têm um peso fundamental por serem os sujeitos que colocarão em atos as demandas da instituição. Assim, os professores são agentes importantes nos laboratórios informatizados, sendo importante analisar o efeito que o computador pode ter em seu processo de trabalho.

tecnologias da comunicação e informação. Em T. M. G Fonseca \& D. J Francisco (Orgs.), Formas de ser e habitar a contemporaneidade (pp. 55-62). Porto Alegre: Ed. Universidade/UFRGS

Oliveira, R. (1997). Informática educativa: dos planos e discursos à sala de aula. Campinas: Papirus.

Pereira, M. V. (2000). Nos supostos para pensar formação e autoformação: a professoralidade produzida no caminho da subjetivação. Em Encontro Nacional de Didática e Prática de ensino (ENDIPE). Ensinar e aprender: sujeitos, saberes e pesquisa.(pp.23-42). Rio de Janeiro: DP\&A

Silva, T. T. (1995). Currículo e identidade social: territórios contestados. Em T. T. da Silva (Org), Alienígenas na sala de aula: uma introdução aos estudos culturais em educação, (pp. 190-207). Petrópolis, RJ: Vozes.

Thornburg, D. (1997). 2020 visões para o futuro da educação. [on line]. Disponível em http://www.tepd.org, data de acesso 05/10/2001.

Varela, J. (1994). O estatuto do saber pedagógico. Em T. T. da Silva (Org), O sujeito da educação: estudos foucaultianos (pp. 86-96). Petrópolis, RJ: Vozes.

Recebido em: 02/11/01

Revisado em: 30/04/02

Aprovado em: 25/09/02 